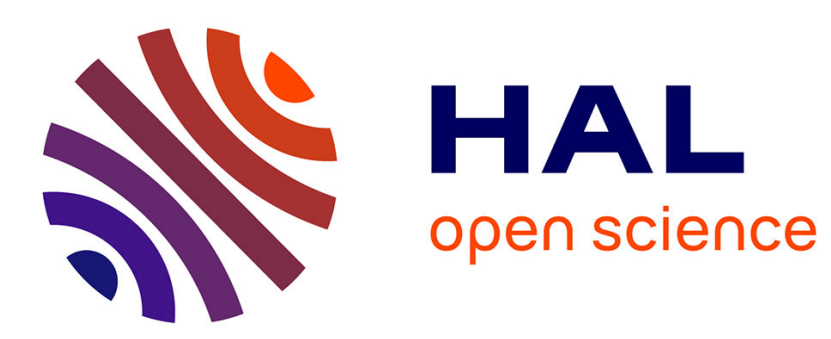

\title{
Is bioenergy trade good for the environment?
}

Jean-Marc Bourgeon, Hélène Ollivier

\section{To cite this version:}

Jean-Marc Bourgeon, Hélène Ollivier. Is bioenergy trade good for the environment?. European Economic Review, 2012, 56 (3), pp.411-421. 10.1016/j.euroecorev.2011.11.002 . hal-00750733

\section{HAL Id: hal-00750733 \\ https://hal.science/hal-00750733}

Submitted on 12 Nov 2012

HAL is a multi-disciplinary open access archive for the deposit and dissemination of scientific research documents, whether they are published or not. The documents may come from teaching and research institutions in France or abroad, or from public or private research centers.
L'archive ouverte pluridisciplinaire HAL, est destinée au dépôt et à la diffusion de documents scientifiques de niveau recherche, publiés ou non, émanant des établissements d'enseignement et de recherche français ou étrangers, des laboratoires publics ou privés. 


\title{
Is bioenergy trade good for the environment?
}

\author{
Jean-Marc Bourgeon ${ }^{\mathrm{a}}$, Hélène Ollivier ${ }^{\mathrm{b}}$ \\ ${ }^{a}$ Corresponding author. INRA and Ecole Polytechnique. Address: AgroParisTech, UMR \\ Économie publique, 16 rue Claude Bernard 75231 Paris Cedex 05, France. E-mail: \\ bourgeon@agroparistech.fr.Tel: 3314408 72 87, Fax: 33144081663 \\ ${ }^{b}$ Dept. of Agricultural and Resource Economics, University of California, 207 Giannini \\ Hall, Berkeley, CA 94720-3310. E-mail: helene.ollivier@berkeley.edu.
}

\begin{abstract}
We analyze the impacts of bioenergy trade on greenhouse gas emissions using a two-good, three-factor model. Bioenergy is an agricultural good used as a substitute for fossil fuels in industry. Governments tax domestic pollution without international coordination. We assume that northern countries have higher labor productivity than southern ones and that agriculture is less pollution intensive than industry (after taxation). We show that whereas southern countries impose a lower tax rate than northern ones, they do not necessary have a competitive advantage in industry, and that compared to autarky, trade liberalization either increases or decreases worldwide emissions depending on regional comparative advantages.
\end{abstract}

Keywords: bioenergy, intermediate product, North-South trade, global pollution

JEL: F18, H23, Q17 


\section{Introduction}

The potential of bioenergy in mitigating greenhouse gas (GHG) emissions from fossil fuels has recently stimulated both the scientific and the political debate (von Lampe, 2006). Bioenergy is a relatively clean renewable alternative to fossil fuels but as an agricultural product (e.g. ethanol and biodiesel), it competes for land and feedstock with food production.1. Moreover, although its use does not emit additional GHG, its production does through the use of fertilizers or chemicals and through the conversion of grasslands and forested lands..$^{2}$ Liberalizing trade of bioenergy could worsen this effect or allow industries to reduce GHG emissions by reducing fossil fuel use.

This paper examines the potential impacts of bioenergy trade, with a focus on the resulting worldwide GHG emissions. We determine the trade equilibrium of a global economy with many countries belonging to two regions, North and South, facing global pollution with no international coordination. The two regions only differ in their effective labor endowment, Northern labor being more productive. Each economy is composed of two sectors, agriculture and industry, that emit GHG. The agricultural sector produces both a final good and an intermediate product, bioenergy. In this sector, pollution arises as an increasing and convex function of land use. Pollution in the other sector, industry, is proportional to the use of fossil fuels. We restrict parameter values so that industry is the pollution intensive sector.

We have two major conclusions. First, we show that in equilibrium the richer country, which imposes higher environmental taxes, may have a comparative advantage in the pollution intensive sector. This possibility arises because of industrial producers' ability to substitute bioenergy for fossil fuels. The second result is that trade may increase or decrease the worldwide level of GHG emissions. The direction of effect depends on which country has a comparative advantage in the dirty sector in trade. A key result is that

\footnotetext{
${ }^{1}$ For instance, to meet a $10 \%$ share of biofuels in domestic transport fuel consumption, the U.S., Canada and the E.U would need to use $30 \%, 36 \%$ and $72 \%$ of their agricultural lands respectively (von Lampe, 2006).

${ }^{2}$ Emissions from land conversion vary depending on the quality of land, on the history of past land-uses and on the amount of carbon sequestrated in the soil and the biomass (Schneider, 2007). A first impact of land conversion is the release of carbon sequestrated in the soil and the biomass (Searchinger et al., 2008, Fargione et al., 2008). A second impact is the reduced sequestration capacity of agricultural land compared to grassland and forest (Birdsey, 1992).
} 
the change in national emissions caused by trade is always greater in South than in North. This result implies that if South has a comparative advantage in industry, trade increases worldwide emissions, whereas if North has a comparative advantage in industry, trade decreases worldwide emissions. We find that North is more likely to have a comparative advantage in industry if bioenergy and fossil fuels are close substitute and if marginal emissions in agriculture rise sharply with land use expansion.

Trade always increases emissions in one region and decreases emissions in the other region. The effect is more pronounced in South than in North, which leads to our contrasting results on worldwide emissions. The reason is as follows. Governments set their environmental regulations independently, taking the other countries' emissions as given. Since North has more effective units of labor, in equilibrium it has a higher income than South. Hence, pollution taxes are always higher in North than in South in equilibrium. We show that regional taxes (and wages) differ in free trade, i.e. the Factor Price Equalization theorem (FPE) does not hold due to the non-linearity of agricultural emissions. As a result, if North exports industrial goods, industry shifts to North where the cleaner technique leads to less aggregate pollution. This effect outweighs the increase in emissions coming from agricultural expansion in South. If, instead, South exports industrial goods, its emissions rise and the global environment deteriorates.

Our set-up is close to Copeland \& Taylor (1995), who find that trade increases worldwide emissions when South has a comparative advantage in the dirty sector and when environmental taxes do not equalize across regions. Our model, however, differs from theirs in two respects. First, the nature of pollution is different across sectors: Whereas industrial emissions are proportional to the use of fossil fuels, agricultural pollution is a convex function of land use. Second, one sector produces both a final good and an intermediate good, as in Vanek (1963), that is used by industry to reduce pollution. These differences also distinguish our set-up from Copeland \& Taylor (1997, 2003), who find that trade impacts on worldwide pollution depend on the patterns of trade. Whereas they consider specific factor models, our set-up can be restated as a Heckscher-Ohlin-Vanek trade model with labor and pollution as inputs and with decreasing returns in agriculture. $3^{3}$ Chua (2003) shows

${ }^{3}$ Copeland \& Taylor (1997) consider economies with two polluting sectors of different emissions intensities, but labor (capital) is used only by the less (most) pollution intensive 
that if there is an abatement sector, the region with the highest environmental tax may have a comparative advantage in the emission-intensive good. An increase in the environmental tax increases the returns of the most intensive factor in the abatement sector. The tax thus affects differently the production costs of the two final-good sectors depending on their respective factor intensities. Chua (2003) considers the impacts of exogenous tax rates on autarky prices, whereas we allow tax rates to be endogenous and solve for the free trade equilibrium.

The remainder of the paper is organized as follows: Section 2 presents the model and Section 3 examines the autarky equilibrium. Section 4 considers the effects of trade on the environment. The last section contains concluding remarks.

\section{The model}

Consider a world economy with two regions (North and South), composed of many countries : $n$ in North and $n^{*}$ in South. In the rest of the paper, we index by " $*$ " the variables corresponding to southern countries. $4^{4}$ All countries within a region are identical. The population size of each country is normalized to 1, but the labor force is more productive in North, leading to a higher effective labor in North than in South: $L>L^{*}$.

Each economy is composed of two sectors: agriculture $(A)$ and industry $(M)$. Both sectors are responsible for GHG emissions, a pollutant leading to global warming and affecting the welfare of the world population. Industry pollutes through the use of fossil fuels. Agriculture indirectly pollutes through the use of land. The agricultural product can be used either as a final food product $(F)$ for consumers or as an intermediate product, bioenergy $(B)$, which enters the production process of industry, with $A=F+B$.

Industry $M$ requires both labor $\left(L_{M}\right)$ and energy as inputs, the latter being a mix of fossil energy $(E)$ and bioenergy. Industrial emissions $\left(Z_{M}\right)$ are proportional to the use of fossil fuels; carbon content is normalized to 1 , so that $Z_{M}=E$. Equivalently, we may consider that there are three inputs: labor, pollution and bioenergy. Assuming a Cobb-Douglas production

sector. In Copeland \& Taylor (2003), labor and capital are used by both sectors, but only one pollutes.

${ }^{4}$ Most of the computations are made for a northern country but are valid for a southern one unless otherwise indicated. 
function in the industrial production, we get

$$
M=L_{M}^{1-\alpha}\left[E^{1-e} B^{e}\right]^{\alpha}=L_{M}^{1-\alpha} Z_{M}^{(1-e) \alpha} B^{e \alpha},
$$

where $0<\alpha<1$ indexes the share of energy uses and $0<e<1$ the share of bioenergy in the energy mix.$^{5}$

The production of $A$ units of agricultural goods is described by

$$
A=K_{A}^{\mu} L_{A}^{1-\mu}
$$

where $L_{A}$ corresponds to labor and $K_{A}$ to land, and where $0<\mu<1$ is the output elasticity of land. Land use $K_{A}$ generates $Z_{A}=\psi\left(K_{A}\right)$ units of GHG emissions with $\psi^{\prime}>0$ and $\psi^{\prime \prime}>0$. In the following, we assume $\psi\left(K_{A}\right)=\zeta K_{A}^{\sigma} / \sigma$, with $\zeta>0$ and $\sigma>1$. The convexity of the agricultural emission function reflects the fact that land conversion reduces the carbon sequestration capacity of soil at an increasing rate, the equilibrium level of carbon in cropland soils being lower than in pasture, which is itself lower than in mature forests (Birdsey, 1992). While some of the carbon released by soil conversion is captured back by the agricultural land in the long run, there are nevertheless losses in the carbon sequestration capacity of soils that correspond to net GHG emissions due to agricultural expansion. 6

It is possible to restate the production process in agriculture as using labor and GHG emissions according to the relation

$$
A=(\sigma / \zeta)^{\mu / \sigma} Z_{A}^{\mu / \sigma} L_{A}^{1-\mu}
$$

which will prove convenient when comparing agriculture with industry. However, (3) cannot be used interchangeably with (2) in solving the problem of the agricultural producer. Indeed, as a function of labor and GHG emissions,

\footnotetext{
${ }^{5}$ We adopt a Cobb-Douglas production function for analytical convenience. The functional form implicitly assumes that bioenergy is a necessary input for manufacturing. Despite its lack of realism, it allows us to focus on the role of an intermediate product that can be used for outsourcing pollution.

${ }^{6} \mathrm{We}$ also assume that these losses are the same in southern and northern countries whereas in fact they may be different even for two countries in the same region. In addition to analytical convenience, this symmetry allows us to illustrate our main point: Even if North is richer and taxes more heavily GHG emissions than South, the competitive advantage of each region depends on the substitutability between energies and on the nonlinearity of emissions in agriculture, not on heterogeneous damages.
} 
(3) exhibits decreasing returns to scale while (2), the relevant production function which involves land and labor as inputs, exhibits constant returns to scale. This difference is of course due to the convexity of the emission function in agriculture.

We assume that GHG emissions harm only consumers. To reduce emissions, governments adopt sectoral policies using sector-specific taxes on input uses: fossil fuel tax $\tau$ for the industry and land tax $\tau_{A}$ for agriculture. 7 The trade-off for industrial producers is between paying the environmental tax and abating pollution, i.e. substituting bioenergy and labor for pollution. To abstract from consideration of stock depletion, we assume that energy and land are available in both regions without restriction. Therefore, the fossil fuel price and the land price correspond to their respective tax: $\tau$ and $\tau_{A}{ }^{8}$ As emissions are proportional to the use of fossil fuels, the tax on fossil fuels $\tau$ equals the carbon tax.

Denote by $w$ the effective labor wage and consider that the agricultural good is the numeraire (i.e. $p_{A}=1$ ). Labor being perfectly mobile within a country (but immobile across countries), the wage is identical across sectors. Given that $p_{A}=1$, the unit-cost of the representative firm in industry simplifies to

$$
c_{M}(w, \tau)=\kappa_{M}\left[w^{1-\xi} \tau^{\xi}\right]^{1-e \alpha},
$$

where $\kappa_{M} \equiv \alpha^{-\alpha}(1-\alpha)^{\alpha-1} e^{-e \alpha}(1-e)^{-(1-e) \alpha}$ is a constant, and where $\xi \equiv$ $(1-e) \alpha /(1-e \alpha)$ corresponds to the "relative"output elasticity of fossil fuels in the following sense. For a given level of biofuel use, consider the increase in industrial production due to simultaneous equal marginal increases in labor and fossil fuels: it is given by the sum of the output elasticities of fossil fuels and labor, $(1-e) \alpha$ and $1-\alpha$ respectively. The relative contribution of fossil fuels in this increase is given by $\xi$ (and $1-\xi=(1-\alpha) /(1-e \alpha)$ corresponds to the contribution of labor). Observe that $\xi$ also corresponds to the share of the fossil fuel tax in the industrial cost net of biofuel expenditure, i.e., $\xi=\tau Z_{M} /\left(\tau Z_{M}+w L_{M}\right)$. Indeed, denoting by $p$ the price of the industrial good, the production cost divides among the inputs following Euler's rule,

\footnotetext{
${ }^{7}$ Considering taxes on the input uses of sectors exhibiting constant returns to scale allows us to analyze bioenergy trade in a competitive trade framework.

${ }^{8} \mathrm{We}$ assume that the government possesses all the information necessary to tax the carbon content of fossil energy used in industry and the land used in agriculture without cost.
} 
i.e.:

$$
\begin{aligned}
\tau Z_{M} & =(1-e) \alpha p M, \\
w L_{M} & =(1-\alpha) p M, \\
B & =\operatorname{e\alpha pM} .
\end{aligned}
$$

The total cost of producing $A$ is $A c_{A}\left(w, \tau_{A}\right)$, where

$$
c_{A}\left(w, \tau_{A}\right)=\kappa_{A} w^{1-\mu} \tau_{A}^{\mu}
$$

and where $\kappa_{A} \equiv \mu^{-\mu}(1-\mu)^{\mu-1}$, which leads to:

$$
\begin{aligned}
w L_{A} & =(1-\mu) A \\
\tau_{A} K_{A} & =\mu A .
\end{aligned}
$$

The share of the environmental tax in the production cost corresponds to the output elasticity of land, i.e., $\mu=\tau_{A} K_{A} /\left(\tau_{A} K_{A}+w L_{A}\right)$. Using (3), the output elasticity of GHG emissions in agriculture is given by $\mu / \sigma$. Comparing $\xi$ and $\mu$ allows us to measure the sectoral wealth effects due to GHG emissions while the difference between $\xi$ and $\mu / \sigma$ compares the relative productive efficiency of GHG emissions in each sector.

As pollution is transboundary, consumers' utility is affected by world pollution $Z^{w}$, the sum of the emissions of North and South : $Z^{w}=Z^{N}+Z^{S}$. Regional variables are indexed by superscripts $N$ for North and $S$ for South. As countries are identical within a region, we have $Z^{N}=n Z$ with $Z=$ $Z_{M}+Z_{A}$ for North. The utility of the representative consumer is given by:

$$
U=b_{A} \ln D_{A}+b_{M} \ln D_{M}-\beta\left(Z^{w}\right)^{\gamma} / \gamma
$$

where $D_{A}$ and $D_{M}$ are the quantities of goods consumed, with $b_{A}+b_{M}=1$. We assume that $\beta>0$ and $\gamma \geq 1$ to ensure that the marginal willingness to pay for abating pollution is a nondecreasing function of world pollution. The corresponding expenditure function is:

$$
E\left(\bar{u}, Z^{w}\right) \equiv \min _{D_{A}, D_{M}}\left\{D_{A}+p D_{M}: U \geq \bar{u}\right\}=E_{0} \exp \left(\bar{u}+\beta\left(Z^{w}\right)^{\gamma} / \gamma\right),
$$

where $E_{0}=\exp \left\{b_{A} \ln b_{A}+b_{M} \ln b_{M}-b_{M} \ln p\right\}$. Demands satisfy $p D_{M}=$ $b_{M} E\left(\bar{u}, Z^{w}\right)$, and $D_{A}=b_{A} E\left(\bar{u}, Z^{w}\right)$, hence $b_{A}$ and $b_{M}$ correspond to the budget shares of food and industrial goods respectively. The balanced budget constraint implies that national expenses $E\left(\bar{u}, Z^{w}\right)$ should not exceed 
national revenue $I$. Assuming the proceeds of the environmental taxes are redistributed to consumers through a lump-sum transfer, we have

$$
I \equiv w L+\tau Z_{M}+\tau_{A} K_{A},
$$

using $L=L_{A}+L_{M}$. Due to the transborder nature of the externality, optimality is not achieved without international coordination. A Nash equilibrium results from the absence of negotiation, each government defining $Z_{M}$ and $Z_{A}$ for its country while considering the emissions from all other countries as exogenous. It imposes taxes on fossil fuels and on land so that the utility of the representative consumer is maximized. Differentiating the balanced budget constraint $E\left(\bar{u}, Z^{w}\right)=I$ allows us to determine the effects of small emission variations $d Z_{M}$ and $d K_{A}$ around their optimal levels. We have, neglecting price effects 9

$$
E\left(\bar{u}, Z^{w}\right)\left[d \bar{u}+\beta\left(Z^{w}\right)^{\gamma-1}\left(d Z_{M}+\psi^{\prime}\left(K_{A}\right) d K_{A}\right)\right]=\tau d Z_{M}+\tau_{A} d K_{A}
$$

At the optimum, $d \bar{u}=0$, which leads to the conditions

$$
\begin{aligned}
\tau & =\beta I\left(Z^{w}\right)^{\gamma-1} \\
\tau_{A} & =\psi^{\prime}\left(K_{A}\right) \tau .
\end{aligned}
$$

Environmental taxes increase with national income and worldwide emissions. The environment is thus a normal good. The land tax also increases with the amount of land used and is equivalent to a (Pigouvian) tax on agricultural emissions: we have $\tau d Z_{A}=\tau \psi^{\prime}\left(K_{A}\right) d K_{A}=\tau_{A} d K_{A}$. Farmers, however, have to pay a tax proportional to the marginal emission level $\psi^{\prime}\left(K_{A}\right)=\zeta K_{A}^{\sigma-1}$, which increases with $K_{A}$ since $\sigma>1$.

By implementing $\tau$ and $\tau_{A}$ the government implicitly defines the emissions supply of the country: using $(12)$ and $\psi^{\prime}\left(K_{A}\right) K_{A}=\sigma Z_{A}$, we get

$$
\frac{\tau}{w}=\frac{\beta L\left(Z^{w}\right)^{\gamma-1}}{1-\beta\left[Z_{M}+\sigma Z_{A}\right]\left(Z^{w}\right)^{\gamma-1}} .
$$

\footnotetext{
${ }^{9}$ Price effects cancel out through market equilibrium conditions in autarky. When considering trade, the same equations hold as long as the government policy has no impact on international prices, i.e. the number of countries is large. We thus abstract from the use of environmental policies as commercial levies.
} 
which depends on the effective labor endowment. Pollution demands are derived from (5)-(10) and (14). We obtain

$$
\begin{aligned}
Z_{A} / L_{A} & =(w / \tau) \mu /[\sigma(1-\mu)] \\
Z_{M} / L_{M} & =(w / \tau) \xi /(1-\xi)
\end{aligned}
$$

for agriculture and industry respectively. Observe that the pollution intensity in agriculture is smaller the higher the elasticity of land use emission $\sigma$. This is the result of the optimal land tax which, given (14), is such that $\tau_{A} K_{A}=\sigma \tau Z_{A}$. Although the marginal taxes on emissions are the same (as noted above), the total tax on land use is higher than its equivalent in terms of carbon emissions because $\sigma>1$. Comparing (16) and (17), the industry is relatively pollution intensive and agriculture labor intensive if

$$
\mu /(1-\mu)<\sigma \xi /(1-\xi)
$$

which is assumed in the rest of the paper. For $e=0$ (no substitution between fossil energy and bioenergy), $\xi=\alpha$ and H1 is satisfied if $\mu<\alpha$. Hence, when it is impossible to substitute bioenergy for fossil fuels, agriculture is cleaner than industry if the output elasticity of land in agriculture is lower than the output elasticity of energy in industry. However, when $e$ is large, close to 1 , i.e. for an industry highly intensive in bioenergy, $\xi$ is very close to 0 and $\mu$ must be very low and $\sigma$ very large for agriculture to be cleaner than industry. Empirical evidence supports the assumption that agriculture is less pollution intensive than industry, although it is not pollution-free. ${ }^{10}$ It is easily obtained that $\mathrm{H} 1$ implies $\xi>\mu / \sigma$, i.e. that the (relative) output elasticity of GHG emissions is larger in industry than in agriculture.

At equilibrium, demand and supply are equal. Pollution demand is related to the consumers' consumption of goods which depends on the openness

\footnotetext{
${ }^{10}$ Schipper et al. (2001) show that agriculture is less carbon intensive than the manufacturing industries in several developed countries. Carbon intensities are measured by the amount of carbon per value added in each sector in 1994. Estimates in the manufacturing sector are $210 \mathrm{gC} / \mathrm{USD}$ in Denmark, $127 \mathrm{gC} / \mathrm{USD}$ in France, and $267 \mathrm{gC} / \mathrm{USD}$ in the U.S., whereas in agriculture they are 110, 37 and 50 respectively. Since the estimates are based on energy consumption, they omit emissions from land use changes and deforestation, in particular the "carbon debt" that represents approximately 17 to 123 times more carbon emissions than the annual savings of fossil fuel replacement from biofuel (Fargione et al. 2008). Schneider \& Smith (2009) also show that emissions intensities vary with agricultural practices and land management changes.
} 
to trade of the countries. As a benchmark, we first investigate the case of autarky. We then detail the effects of trade.

\section{Autarky and comparative advantages}

Under autarky, both regions consume only locally produced goods. Market equilibria give $p M=p D_{M}=b_{M} I$ and $A=D_{A}+B=\left[b_{A}+e \alpha b_{M}\right] I$. Using $\tau Z_{M}=(1-e) \alpha b_{M} I, \tau_{A} K_{A}=\mu\left(e \alpha b_{M}+b_{A}\right) I$, (13) and (14), lead to the pollution demand from each sector:

$$
\begin{aligned}
Z_{M} & =(1-e) \alpha b_{M} /\left[\beta\left(Z^{w}\right)^{\gamma-1}\right] \\
Z_{A} & =\mu\left(e \alpha b_{M}+b_{A}\right) /\left[\sigma \beta\left(Z^{w}\right)^{\gamma-1}\right] .
\end{aligned}
$$

Consequently, the national demand of pollution is given by

$$
Z=Z_{M}+Z_{A}=\theta /\left[\beta\left(Z^{w}\right)^{\gamma-1}\right]
$$

where $\theta \equiv(1-e) \alpha b_{M}+\mu\left(e \alpha b_{M}+b_{A}\right) / \sigma$. Pollution demands depend on the world pollution level and on parameters that are the same in both regions. Hence, despite their difference in income, northern and southern emission levels are the same under autarky: $Z=Z^{*}=Z^{a}$. This result is due to the combination of fixed shares of income spent in final good consumption and of fixed shares of production cost spent in environmental taxes (Cobb-Douglas functional forms) ${ }^{11}$ Expressions (18), (19) and (20) show that the GHG emissions of a country decrease with the worldwide emissions level $Z^{w} \cdot{ }^{12}$ The resulting world level of GHG emissions under autarky is given by

$$
Z^{w a}=\left(n+n^{*}\right) Z^{a}=\left[\left(n+n^{*}\right) \theta / \beta\right]^{1 / \gamma} .
$$

Consequently, we have the following result:

\footnotetext{
${ }^{11}$ Because North is richer, its economies have a larger scale than in South, which tends to increase emissions (scale effect). North, however, is also more prone to tax pollution, which makes its production cleaner (technical effect). These two effects exactly offset each other in the case of the Cobb-Douglas utility function. This functional form also implies constant shares of expenses in the final goods, thus there is no composition effect at work in autarky (see Copeland and Taylor 2003 for a more detailed presentation of these effects).

${ }^{12} \mathrm{As} Z^{w}$ is the sum of emissions of all countries, the levels given by 18$),(19)$ and $(20)$ are defined only implicitly: these equations do not correspond to "best reply functions" of a particular country to the GHG emissions strategy of the other countries.
} 
Proposition 1. Under autarky, northern and southern countries use the same amount of land and emit the same level of pollution.

Under autarky, pollution is not a distinctive pattern for North and South: sector emissions of GHG are identical from one country to another. Of course, as effective labor endowments in South are lower than in North, emission intensities are larger in South than in North. Using (8), (13), (14) and (15), we obtain that

Proposition 2. Under autarky, relative factor prices are higher in North: $(\tau / w) /\left(\tau^{*} / w^{*}\right)=L / L^{*}>1$, and the environmental taxes and the national income are higher in North: $\tau_{A} / \tau_{A}^{*}=\tau / \tau^{*}=I / I^{*}=\left(L / L^{*}\right)^{1-\mu}>1$, whereas the effective labor wage is lower in North: $w / w^{*}=\left(L^{*} / L\right)^{\mu}<1$.

Because of a larger effective labor endowment, income and environmental taxes (wages) are larger (lower) in North than in South in autarky. These discrepancies depend on the relative labor endowment and on $\mu$. The higher the output elasticity of land, the lower the wages and the taxes in North compared to South, but these effects cancel out when considering the ratio of factor prices.

Gains from trade depend on each region's comparative advantage. Since North has a larger labor endowment while pollution levels are the same, relative factor abundance theory predicts that in trade, North specializes in labor-intensive agriculture whereas South specializes in pollution-intensive industry under H1. However, using (4) we obtain

$$
c_{M}(w, \tau) / c_{M}\left(w^{*}, \tau^{*}\right)=\left(L^{*} / L\right)^{(\mu-\xi)(1-e \alpha)} .
$$

As a consequence, North has a comparative advantage in industry iff $\mu>\xi$. $^{13}$ This condition is compatible with $\mathrm{H1}$ if $\sigma>1$. More precisely,

Lemma 1. Southern countries have a comparative advantage in the labor intensive agriculture and northern countries in the GHG intensive industry if $\mu, \xi$ and $\sigma$ satisfy

$$
\sigma \xi /[1+(\sigma-1) \xi]>\mu>\xi .
$$

If $\xi>\mu$, southern countries have a comparative advantage in the GHG intensive industry and northern countries in agriculture.

\footnotetext{
${ }^{13}$ Only industrial costs differ across regions since the agricultural good is the numeraire.
} 
Since $\xi$ is decreasing in $e$, the more substitutable fossil fuels and bioenergy are, the more likely North has a comparative advantage in industry. Industry, however, must remain the most pollution intensive sector after substituting bioenergy for pollution. A higher GHG emissions rate in agriculture $\sigma$ makes it easier for this condition to hold since the environmental tax is more stringent in agriculture.

Figure 1 illustrates the two possible cases ${ }^{14} \mu>\xi$ leads to a steeper industrial iso-cost curve relative to the agricultural curve and corresponds to intensities satisfying $\sigma Z_{A} / L_{A}>Z_{M} / L_{M}>Z_{A} / L_{A}$. On the opposite, $\mu<\xi$ leads to a steeper iso-cost curve in agriculture than in industry, and we have $Z_{M} / L_{M}>\sigma Z_{A} / L_{A}$ under H1. As $\sigma>1$, industry is more pollution intensive than agriculture in any case. Since land use is the same in both regions, agricultural iso-cost curves are identical. However, the industrial isocost curve of the region with a comparative advantage in industry is located below the other. In both situations, the factor price ratio $(\tau / w)$ is larger in North than in South.

This ambiguity in the patterns of trade has not received much attention, except in Copeland \& Taylor (1997, 2003) and Chua (2003). Usually, trade liberalization will see South having a comparative advantage in the emission intensive good and North in the "cleaner" good. But the non-linearity of the emission due to land conversion implies that agriculture could have a flatter iso-cost curve than in industry.

A higher environmental tax impacts both sectors through the input prices $\tau$ and $\tau_{A}$, but the resulting effect on the output relative price is intricate. In industry, the rise in the energy prices implies that it is more costly to produce industrial goods even if it is possible to substitute bioenergy for fossil fuels. In agriculture, since $\tau_{A}=\tau \psi^{\prime}\left(K_{A}\right)$, the land price is affected directly through the change in $\tau$ but also through the change in the demand for bioenergy which may result in a higher demand for land. When $\sigma$ is large, the impact on the agricultural price of a higher tax exceeds the impact on the industrial price. Consequently, a tighter environmental policy induces a

\footnotetext{
${ }^{14}$ Using (4), (8) and (14), the slopes of the iso-cost curves are given by $\left.(d \tau / d w)\right|_{c_{M}=p}=$ $-(\tau / w)(1-\xi) / \xi=-L_{M} / Z_{M}$ for industry and by $\left.(d \tau / d w)\right|_{c_{A}=1}=-(\tau / w)(1-\mu) / \mu=$ $-L_{A} /\left(\sigma Z_{A}\right)$ for agriculture. The latter does not correspond to the inverse of the pollution intensity in this sector since the Shepard lemma does only apply to inputs chosen by the farmer: $L_{A}$ and $K_{A}=\psi^{-1}\left(Z_{A}\right)$. We thus have $-\left.(d \tau / d w)\right|_{c_{A}=1}=$ $\left(\partial c_{A} / \partial w\right) /\left(\partial c_{A} / \partial \tau\right) / \psi^{\prime}\left(K_{A}\right)=\sigma^{-1} L_{A} / Z_{A}$.
} 
decrease (a rise) in the relative price $p$ when $\sigma$ is large (small), which explains the potential for reversing comparative advantages.

\section{Trade impacts on the environment}

A first appraisal of trade impacts on the environment is deduced from the sectorial emission demands (16) and (17) and the government pollution supply (15). Indeed, using the labor market equilibrium we get

$$
Z_{A} \sigma / \mu+Z_{M} / \xi=\left(Z^{w}\right)^{1-\gamma} / \beta
$$

which holds regardless of the country's openness to trade and whatever $Z^{w}$. Indicating with superscript " $t$ " trade equilibrium values, we thus have $Z_{M}^{t}-$ $Z_{M}^{* t}=\left(Z_{A}^{* t}-Z_{A}^{t}\right) \xi \sigma / \mu$. Hence, if $Z_{M}^{t}>Z_{M}^{* t}$ we also have $Z_{A}^{* t}>Z_{A}^{t}$ : if industrial emissions are larger in North than in South (as we may expect if $\mu>\xi)$, agricultural emissions will be larger in South than in North, and reciprocally if comparative advantages are the opposite. Moreover, as $\xi>$ $\mu / \sigma$ under $\mathrm{H} 1$, we have $\left\|Z_{M}^{t}-Z_{M}^{* t}\right\| \geq\left\|Z_{A}^{* t}-Z_{A}^{t}\right\|$, and the inequality is strict if trade induces a discrepancy of sector emissions between countries. Hence, if $Z_{M}^{t}>Z_{M}^{* t}$, we have $Z^{t}=Z_{M}^{t}+Z_{A}^{t}>Z_{M}^{* t}+Z_{A}^{* t}=Z^{* t}$, whereas if $Z_{M}^{* t}>Z_{M}^{t}$, we have $Z^{* t}>Z^{t}$. Consequently, under $\mathrm{H} 1$.

Lemma 2. Trade liberalization induces a higher GHG emissions level in countries that have a comparative advantage in industry.

The effects of trade on the emission patterns are derived using the iceberg cost approach (Samuelson, 1954) of trade frictions which take the form of a "shrinkage" of the industrial goods in transit so that only a fraction of the items shipped abroad actually arrives $\sqrt{15}$ The presence of iceberg costs implies that industrial good prices differ when all countries are open to trade: we have $p_{M}^{*}=\omega p_{M}$, where $\omega$ is the trade coefficient. Considering the case of a diversified equilibrium (which supposes that labor endowments are not too different), trade implies that $c_{M}\left(w^{*}, \tau^{*}\right)=\omega c_{M}(w, \tau)$ and $c_{A}\left(w^{*}, \tau_{A}^{*}\right)=$

\footnotetext{
${ }^{15}$ To simplify computations, we assume that there is no friction in the transport of agricultural goods which also allows us to have the same numeraire in every countries.
} 
$c_{A}\left(w, \tau_{A}\right) \cdot{ }^{16}$ Consequently, using $(14)$, we obtain the relative factor prices

$$
\begin{aligned}
\tau / \tau^{*} & =\left(K_{A} / K_{A}^{*}\right)^{-\nu(1-\xi)} \vartheta^{1-\mu} \\
w / w^{*} & =\left(K_{A} / K_{A}^{*}\right)^{\nu \xi} \vartheta^{-\mu},
\end{aligned}
$$

where $\nu \equiv \mu(\sigma-1) /(\mu-\xi)$ and $\vartheta \equiv \omega^{\xi /[\alpha(1-e)(\mu-\xi)]}$. Free trade corresponds to $\vartheta=1$ while there is no trade if $\vartheta \geq \bar{\vartheta} \equiv L / L^{*}$. Hence, relevant values for $\vartheta$ belong to $[1, \bar{\vartheta}]$, and raising $\vartheta$ increases trade frictions.

From (5) and (10), we obtain that at the trade equilibrium

$$
\tau Z_{M}^{N}+\tau_{A} K_{A}^{N}+\tau^{*} Z_{M}^{S}+\tau_{A}^{*} K_{A}^{S}=\phi\left(I^{N}+I^{S}\right),
$$

where $\phi \equiv(1-e) \alpha b_{M}+\mu\left(e \alpha b_{M}+b_{A}\right)$ is the share of environmental taxes in global income. Using (12), North's relative shares in global income, wages and tax revenues of each region, denoted by $\delta_{I} \equiv I^{N} /\left(I^{N}+I^{S}\right)$, $\delta_{L}=w L^{N} /\left[(1-\phi)\left(I^{N}+I^{S}\right)\right]$, and $\delta_{Z}=\left(\tau Z_{M}^{N}+\tau_{A} K_{A}^{N}\right) /\left[\phi\left(I^{N}+I^{S}\right)\right]$ respectively, satisfy

$$
\delta_{I}=(1-\phi) \delta_{L}+\phi \delta_{Z}
$$

Hence, the northern share of global income is a weighted sum of the northern shares of revenues from labor wages and from environmental taxes. Use of (14) and (25) gives the inverse pollution demand in trade:

$$
\frac{\tau}{w}=\frac{\phi}{1-\phi} \frac{\delta_{Z}}{\delta_{L}} \frac{L}{Z_{M}+\sigma Z_{A}} .
$$

Equalizing supply (15) and demand (26) of pollution, and using (22), gives

$$
\begin{aligned}
Z_{M}^{t} & =\frac{\xi\left(\mu-\phi \delta_{Z} / \delta_{I}\right)}{(\mu-\xi) \beta\left(Z^{w}\right)^{\gamma-1}} \\
Z_{A}^{t} & =\frac{\mu\left(\phi \delta_{Z} / \delta_{I}-\xi\right)}{\sigma(\mu-\xi) \beta\left(Z^{w}\right)^{\gamma-1}},
\end{aligned}
$$

which, given 25) and $\theta=(\mu-\xi \sigma) \phi+\xi \mu(\sigma-1) /[\sigma(\mu-\xi)]$, amount to a domestic pollution level satisfying

$$
Z^{t}=\frac{\theta}{\beta\left(Z^{w}\right)^{\gamma-1}}\left[1+\frac{\phi(1-\phi)}{\theta} \frac{\xi-\mu / \sigma}{\mu-\xi} \frac{\delta_{L}-\delta_{Z}}{\delta_{I}}\right] .
$$

\footnotetext{
${ }^{16} \mathrm{As} \psi^{\prime}(0)=0$, the land price is negligible when only low levels of land are involved and thus both regions produce the agricultural good. However, it may be the case that some countries specialize in agriculture.
} 
Expressions similar to (27) and (28) are obtained for a southern country by replacing $\delta_{i}$ by $1-\delta_{i}$, with $i=Z, I, L$, and we have

$$
Z^{* t}=\frac{\theta}{\beta\left(Z^{w}\right)^{\gamma-1}}\left[1-\frac{\phi(1-\phi)}{\theta} \frac{\xi-\mu / \sigma}{\mu-\xi} \frac{\delta_{L}-\delta_{Z}}{1-\delta_{I}}\right] .
$$

Finally, adding $(29)$ and $(30)$ and rearranging terms gives

$$
Z^{w t}=Z^{w a}\left[1+\frac{\phi(1-\phi)}{\theta} \frac{\xi-\mu / \sigma}{\mu-\xi} \frac{\delta_{L}-\delta_{Z}}{\delta_{I}\left(1-\delta_{I}\right)}\left(\frac{n}{n+n^{*}}-\delta_{I}\right)\right]^{1 / \gamma}
$$

Comparing (20) with (29) and (30) suggests that the emissions of a northern and a southern country are also decreasing with worldwide emission level $Z^{w}$ in trade. Inspection of (29), (30) and (31) reveals that the trade effects depend both on the discrepancies between $\mu$ and $\xi$ and between $\delta_{Z}$ and $\delta_{L}$. It is easily deduced from proposition 2 that $\delta_{Z}=\delta_{I}=\delta_{L}$ under autarky, and thus that (20) is a particular case of both expressions $(29)$ and (30). If trade induces a discrepancy between $\delta_{Z}$ and $\delta_{L}$ (which is the case, as shown below), emissions of northern and southern countries are affected in opposite directions.

Under free trade, i.e. when $\vartheta=1$, we obtain the following result: ${ }^{17}$

Proposition 3. Under diversified free trade,

i) the use of land is different depending on the region: $K_{A}^{* t}>K_{A}^{t}$ iff $\mu>\xi$.

ii) whatever the comparative advantage of each region, we have $I>I^{*}$, $\tau>\tau^{*}$ and $w<w^{*}$.

Proof: see the appendix.

Factor prices differ across regions under free trade, hence the FPE theorem does not hold in our context. Moreover, since North is richer than South in free trade, it has a greater carbon tax than South: $\tau>\tau^{*}$, whatever the comparative advantage of each region.

Figure 2 illustrates the free trade equilibrium, panel $2 a$ corresponding to $\mu>\xi$ and panel $2 \beta$ to $\xi>\mu$. The industrial iso-cost curves are identical

\footnotetext{
${ }^{17}$ The effects of trade liberalization, i.e. a decrease in $\vartheta$ from $\bar{\vartheta}$ are detailed in Bourgeon \& Ollivier (2011)
} 
across regions whereas the agricultural iso-cost curves differ due to the difference in land use. When $\mu>\xi$, South exploits its comparative advantage in agriculture, its iso-cost curve is thus lower than the northern one since the amount of productive land is higher in South. The situation is reversed when $\mu<\xi$. As in figure 1, the factor price ratio is larger in North than in South in both cases.

Denoting by $z^{a}\left(Z^{w}\right), z^{t}\left(Z^{w}\right)$ and $z^{* t}\left(Z^{w}\right)$ the LHS of (20), (29), (30) respectively, it is easily obtained that

$$
n\left\|z^{t}\left(Z^{w}\right)-z^{a}\left(Z^{w}\right)\right\|=n^{*}\left\|z^{* t}\left(Z^{w}\right)-z^{* a}\left(Z^{w}\right)\right\|\left(I^{*} / I\right) .
$$

From proposition 3 and using (32), we can infer that trade impacts on the environment depend on the comparative advantage of each region:

Proposition 4. Under diversified free trade,

if if North (South) has a comparative advantage in industry (agriculture), northern emissions increase, southern emissions decrease, and the worldwide emission level decreases.

ii) If North (South) has a comparative advantage in agriculture (industry), northern emissions decrease, southern emissions increase, and the worldwide emission level increases.

Proof: see the appendix.

Given $I>I^{*}$ and $(32)$, trade has a larger effect on southern emissions than on northern ones: compared to autarky, the variation of the GHG emissions in South more than compensate the change in North. If trade increases emissions in North, it also reduces more importantly emissions in South, leading to a decrease of worldwide emissions. Reciprocally, if trade reduces emissions in North, the large increase in emissions in South results in a larger level of GHG emissions worldwide. Figure 3illustrates the case when northern emissions rise in trade (assuming $n=n^{*}$ in this figure): we have $z^{t}\left(Z^{w}\right)>z^{a}\left(Z^{w}\right)>z^{* t}\left(Z^{w}\right)$. At level $Z^{w a}$, we have $n z^{t}\left(Z^{w a}\right)+n^{*} z^{* t}\left(Z^{w a}\right)<$ $\left(n+n^{*}\right) z^{a}\left(Z^{w a}\right)=Z^{w a}$, implying that trade reduces worldwide emissions (hence a resulting level $Z^{w t}<Z^{w a}$ ).

If North has a comparative advantage in industry, its total level of emissions is larger in trade than in autarky. Even though northern industries 
use more bioenergy than southern ones, the positive trade impact on the global environment owes more to the relocation of southern industries than to northern efforts in using more bioenergy. By contrast, when South has a comparative advantage in industry, trade deteriorates the global environment. Facing a lower environmental tax, southern industries use less bioenergy per unit of industrial good than northern ones. As a consequence, the demand for bioenergy inputs and the international market for bioenergy are likely to be small.

\section{Conclusion}

Trade of commodities and bioenergy has an impact on the environment which can be beneficial if North has a comparative advantage in industry. In that case, the level of global GHG emissions is reduced compared to autarky, while it is increased if South is the most industrial region. These opposite impacts rest on differences in environmental taxes, since the tax is higher in North than in South at equilibrium whatever the comparative advantage. When North is the industrial region, because of its more stringent environmental regulation, the reallocation of pollution-intensive industries in the northern countries result in an improved worldwide environmental situation. Hence, considering the quality of the environment in terms of GHG emission levels alone allows us to conclude on the positive impact of trade if North is the industrial region. This view, however, excludes other aspects of land use changes which are not accounted for in the GHG emissions, such as biodiversity loss, soil erosion and ecosystem disturbances.

We also assume that no country has the capability to influence the terms of trade whereas a few countries dominate the bioenergy market currently. ${ }^{18}$ A major exporter of bioenergy could benefit from an increase in the relative price of these goods (Rauscher, 1994; Copeland \& Taylor, 1995) and thus would have an incentive to increase its land tax while decreasing its carbon tax. As a result, the impacts of trade on the world pollution level would diminish when terms-of-trade effects are taken into account.

\footnotetext{
${ }^{18}$ For example, of the 2.8 billion liters of ethanol exports globally in 2008, Brazil exported 97 percent, primarily to Europe, Japan, India, and the U.S. (Source: 'World Biofuel Maritime Shipping Study', by IEA Bioenergy Task 40, April 2009. www.bioenergytrade.com).
} 


\section{Acknowledgements}

Helene Ollivier acknowledges receiving a S.V. Ciriacy-Wantrup Postdoctoral Fellowship at the department of Agricultural and Resource Economics, University of California, Berkeley. She is also grateful for financing from AgFoodTrade, a project supported by the EU Commission (212036, 2008), and from the Chaire du Développement Durable of the Ecole Polytechnique, France.

\section{References}

Birdsey, R. A. (1992). Carbon storage and accumulation in united states forest ecosystems. United States Department of Agriculture, General Technical Report(WO-59).

Bourgeon, J.-M. \& Ollivier, H. (2011). Is bioenergy trade good for the environment? (long version). Working Paper. See http://web.me.com/hollivier/helene.ollivier/Research.html.

Chua, S. (2003). Does tighter environmental policy lead to a comparative advantage in less polluting goods? Oxford Economic Papers, 55(1), 25-35.

Copeland, B. \& Taylor, M. (1997). A simple model of trade, capital mobility, and the environment. NBER Working Paper, 5898.

Copeland, B. \& Taylor, S. (1995). Trade and transboundary pollution. The American Economic Review, 85, 716-737.

Copeland, B. \& Taylor, S. (2003). Trade and the Environment: Theory and Evidence. Princeton University Press.

Fargione, J., Hill, J., Tilman, D., Polasky, S., \& Hawthorne, P. (2008). Land Clearing and the Biofuel Carbon Debt. Science, 319(5867), 1235.

Rauscher, M. (1994). On environmental dumping. Oxford Economic Papers, $46,822-840$.

Samuelson, P. A. (1954). The transfer problem and transport costs, ii: Analysis of effects of trade impediments. The Economic Journal, 64(254), 264289. 
Schipper, L., Murtishaw, S., Khrushch, M., Ting, M., Karbuz, S., \& Unander, F. (2001). Carbon emissions from manufacturing energy use in 13 iea countries: long-term trends through 1995. Energy Policy, 29(9), 667 688 .

Schneider, U. \& Smith, P. (2009). Energy intensities and greenhouse gas emission mitigation in global agriculture. Energy Efficiency, 2, 195-206. $10.1007 / \mathrm{s} 12053-008-9035-5$.

Schneider, U. A. (2007). Soil organic carbon changes in dynamic land use decision models. Agriculture, Ecosystems \& Environment, 119(3-4), 359 367.

Searchinger, T., Heimlich, R., Houghton, R., Dong, F., Elobeid, A., Fabiosa, J., Tokgoz, S., Hayes, D., \& Yu, T. (2008). Use of US croplands for biofuels increases greenhouse gases through emissions from land-use change. Science, 319(5867), 1238.

Vanek, J. (1963). Variable factor proportions and inter-industry flows in the theory of international trade. The Quarterly Journal of Economics, 77(1), 129-142.

von Lampe, M. (2006). Agricultural market impacts of future growth in the production of biofuels. OECD Working Papers AGR/CA/APM, (pp. 1 $55)$. 


\section{Appendix}

\section{Appendix A. Proof of Proposition 3}

We first determine the relative shares of income $\delta_{Z}, \delta_{L}$ and $\delta_{I}$ using (13), 23), 24) and 25. We get $\delta_{I}=\left[1+\left(n^{*} / n\right)\left[K_{A} / K_{A}^{*}\right]^{\nu(1-\xi)} \vartheta^{-(1-\mu)}\right]^{-1}, \delta_{Z}=$ $\left[\delta_{I}-(1-\phi) \delta_{L}\right] / \phi$ and $\delta_{L}=\left[1+\left(L^{S} / L^{N}\right)\left[K_{A} / K_{A}^{*}\right]^{-\nu \xi} \vartheta^{\mu}\right]^{-1}$. We also have

$$
\frac{\delta_{L}}{\delta_{I}}=\frac{1+\left(n^{*} / n\right)\left(\tau^{*} / \tau\right)}{1+\left(L^{S} / L^{N}\right)\left(w^{*} / w\right)}=\frac{1+\left(n^{*} / n\right)\left[K_{A} / K_{A}^{*}\right]^{\nu(1-\xi)} \vartheta^{-(1-\mu)}}{1+\left(L^{S} / L^{N}\right)\left[K_{A} / K_{A}^{*}\right]^{-\nu \xi} \vartheta^{\mu}}
$$

and symmetrically, $\phi\left(1-\delta_{Z}\right) /\left(1-\delta_{I}\right)=1-(1-\phi)\left(1-\delta_{L}\right) /\left(1-\delta_{I}\right)$ where

$$
\frac{1-\delta_{L}}{1-\delta_{I}}=\frac{\left(L^{S} / L^{N}\right)\left[K_{A} / K_{A}^{*}\right]^{-\nu \xi}}{\left(n^{*} / n\right)\left[K_{A} / K_{A}^{*}\right]^{\nu(1-\xi)}} \vartheta \frac{\delta_{L}}{\delta_{I}} .
$$

These two equations and (28) for North and South lead to a ratio of land use $K_{A} / K_{A}^{*}$ thats solves at equilibrium:

$$
\left[\frac{K_{A}}{K_{A}^{*}}\right]^{\sigma}=\frac{1-\xi-(1-\phi) \Delta\left(K_{A} / K_{A}^{*}\right)}{1-\xi-(1-\phi) \Delta\left(K_{A} / K_{A}^{*}\right)\left[K_{A} / K_{A}^{*}\right]^{-\nu}\left(L^{*} / L\right) \vartheta}
$$

where

$$
\Delta(k)=\frac{1+\left(n^{*} / n\right) k^{\nu(1-\xi)} \vartheta^{-(1-\mu)}}{1+\left(L^{S} / L^{N}\right) k^{-\nu \xi} \vartheta^{\mu}} .
$$

Without trade frictions, $\vartheta=1$ and A.3 can be expressed as $\Omega\left(K_{A} / K_{A}^{*}, L^{*} / L\right)=$ 0 where

$$
\Omega(k, \ell) \equiv k^{\sigma}-\hat{g}(k, \ell)
$$

with

$$
\hat{g}(k, \ell)=\frac{1 / \xi-1-\hat{f}(k, \ell)}{1 / \xi-1-\hat{f}(k, \ell) k^{-\nu} \ell}
$$

and

$$
\hat{f}(k, \ell)=(1-\phi) \frac{1+\left(n^{*} / n\right) k^{\nu(1-\xi)}}{\xi\left[1+\left(n^{*} / n\right) \ell / k^{\nu \xi}\right]} .
$$

As $\nu=\mu(\sigma-1) /(\mu-\xi)$, factor prices equalize only if $K_{A}=K_{A}^{*}$. As $\Omega(1,1)=0$, this is the case for $L=L^{*}$. We first show that this is the only 
case, i.e. $\Omega(1, \ell) \neq 0$ for all $\ell \in(0,1)$. The condition $\Omega(1, \ell)=0$ can be written $\hat{g}(1, \ell)=1$. As

$$
\frac{\partial \hat{g}(k, \ell)}{\partial \ell}=-\frac{\partial \hat{f}(k, \ell)}{\partial \ell} \frac{(1 / \xi-1)\left(1-k^{-\nu} \ell\right)}{\left[1 / \xi-1-\hat{f}(k, \ell) k^{-\nu} \ell\right]^{2}}+\frac{\hat{f}(k, \ell) k^{-\nu}[1 / \xi-1-\hat{f}(k, \ell)]}{\left[1 / \xi-1-\hat{f}(k, \ell) k^{-\nu} \ell\right]^{2}}
$$

where

$$
\frac{\partial \hat{f}(k, \ell)}{\partial \ell}=-\hat{f}(k, \ell) \frac{\left(n^{*} / n\right) k^{-\nu \xi}}{1+\left(n^{*} / n\right) \ell / k^{\nu \xi}}
$$

we have

$$
\frac{\partial \hat{g}(1, \ell)}{\partial \ell}=\frac{\hat{f}(1, \ell)}{[1 / \xi-1-\hat{f}(1, \ell) \ell]^{2}}\left\{(1 / \xi-1)(1-\ell) \frac{\left(n^{*} / n\right)}{1+\left(n^{*} / n\right) \ell}+1 / \xi-1-\hat{f}(1, \ell)\right\}
$$

where the bracketed term is positive if

$$
\hat{f}(1, \ell)<(1 / \xi-1)\left\{\frac{(1-\ell)\left(n^{*} / n\right)}{1+\left(n^{*} / n\right) \ell}+1\right\}=(1 / \xi-1) \frac{1+\left(n^{*} / n\right)}{1+\left(n^{*} / n\right) \ell}
$$

which leads to the condition $0>\xi-\phi=(\xi-\mu)\left[1-(1-e \alpha) b_{M}\right]$. Hence, if $\mu<\xi(\mu>\xi), \hat{g}(1, \ell)$ is decreasing (increasing) in $\ell$. In either case, $\hat{g}(1, \ell)$ is monotonic in $\ell$, implying that $K_{A}=K_{A}^{*}$ only for $L=L^{*}$. We now characterize $K_{A} / K_{A}^{*}$ when $L^{*} / L$ is close to 1 . Using the implicit function theorem, we have $K_{A} / K_{A}^{*}=\hat{k}\left(L^{*} / L\right)$ where $\hat{k}(\ell)$ is a function satisfying $\hat{k}(1)=1$ and

$$
\hat{k}^{\prime}(\ell)=\frac{\partial \hat{g}(\hat{k}(\ell), \ell) / \partial \ell}{\sigma \hat{k}(\ell)^{\sigma-1}-\partial \hat{g}(\hat{k}(\ell), \ell) / \partial k} .
$$

We have

$$
\frac{\partial \hat{g}(k, \ell)}{\partial k}=-\frac{\partial \hat{f}(k, \ell)}{\partial k} \frac{(1 / \xi-1)\left(1-k^{-\nu} \ell\right)}{\left[1 / \xi-1-\hat{f}(k, \ell) k^{-\nu} \ell\right]^{2}}-\frac{\nu \xi \hat{f}(k, \ell) k^{-(\nu+1)} \ell \hat{g}(k, \ell)}{1-\xi-\xi \hat{f}(k, \ell) k^{-\nu} \ell},
$$

hence

$$
\frac{\partial \hat{g}(1,1)}{\partial k}=\frac{-\nu \hat{f}(1,1)}{1 / \xi-1-\hat{f}(1,1)}=\frac{\nu(1-\phi)}{\xi-\phi}=\frac{-\mu(1-\phi)(\sigma-1)}{(\mu-\xi)^{2}\left[1-(1-e \alpha) b_{M}\right]}<0 .
$$

We thus have $\hat{k}^{\prime}(1)>0$ (implying $K_{A}<K_{A}^{*}$ ) when $\partial \hat{g}(1,1) / \partial \ell>0$, i.e. when $\mu>\xi$, and the opposite when $\mu<\xi$. As $K_{A}^{*}>K_{A}$ and $\nu>0$ when $\mu>\xi$ and $K_{A}^{*}<K_{A}$ and $\nu<0$ when $\mu<\xi$, we deduce from (23) and (24) that we always have $\tau>\tau^{*}$ and $w<w^{*}$. From (13), it comes $I>I^{*}$. 

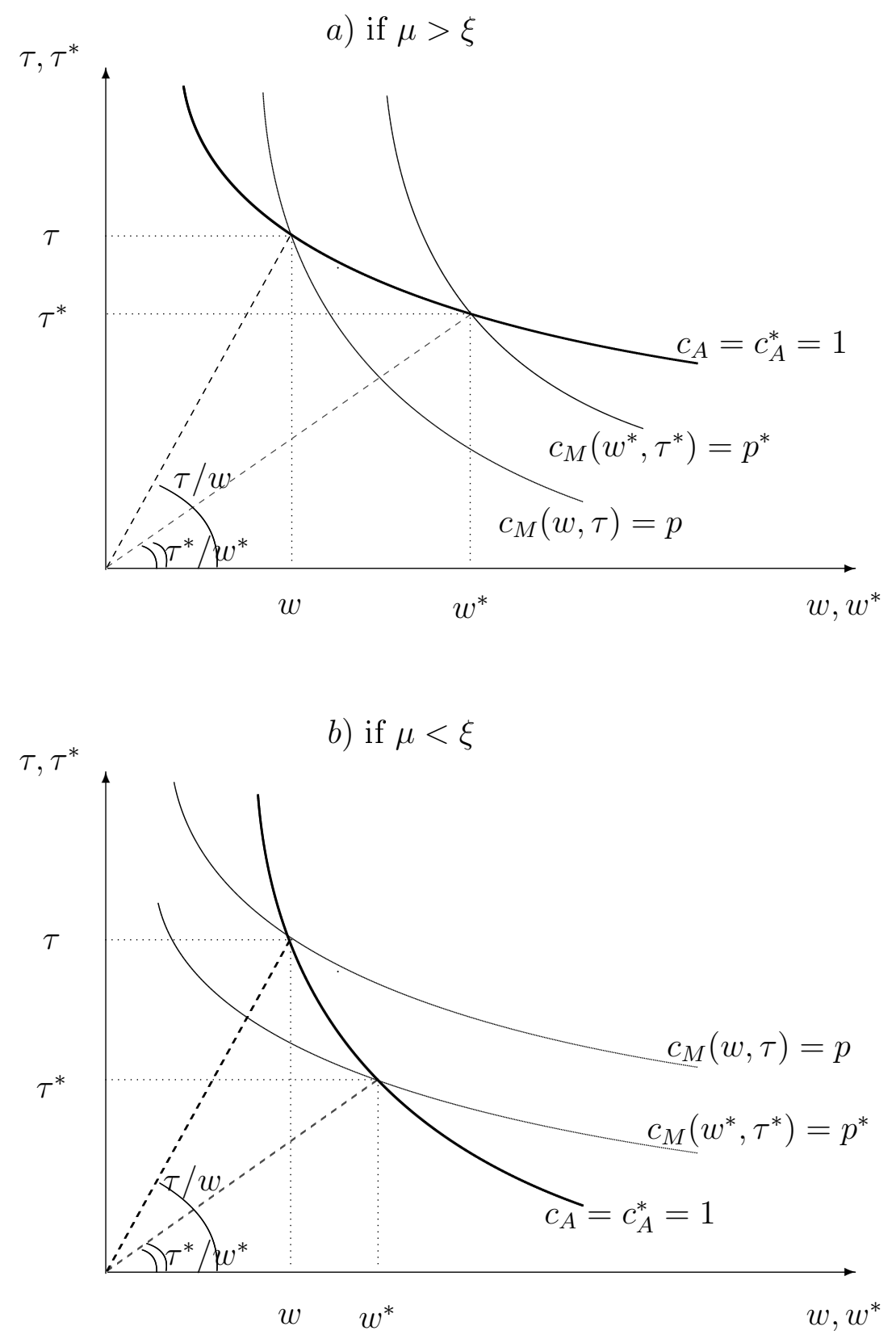

Figure 1: Factor prices under autarky. 

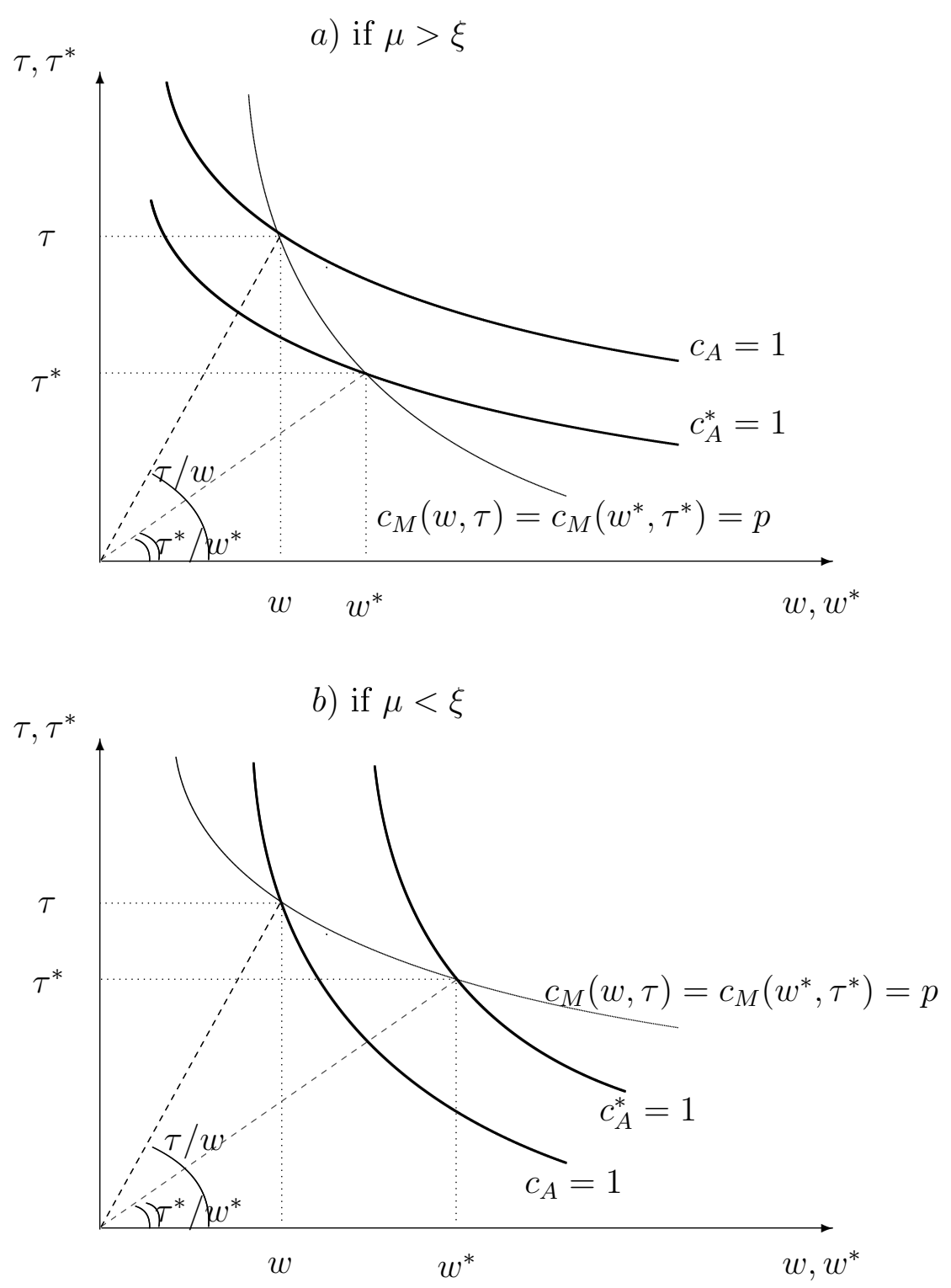

Figure 2: Factor prices under free trade. 


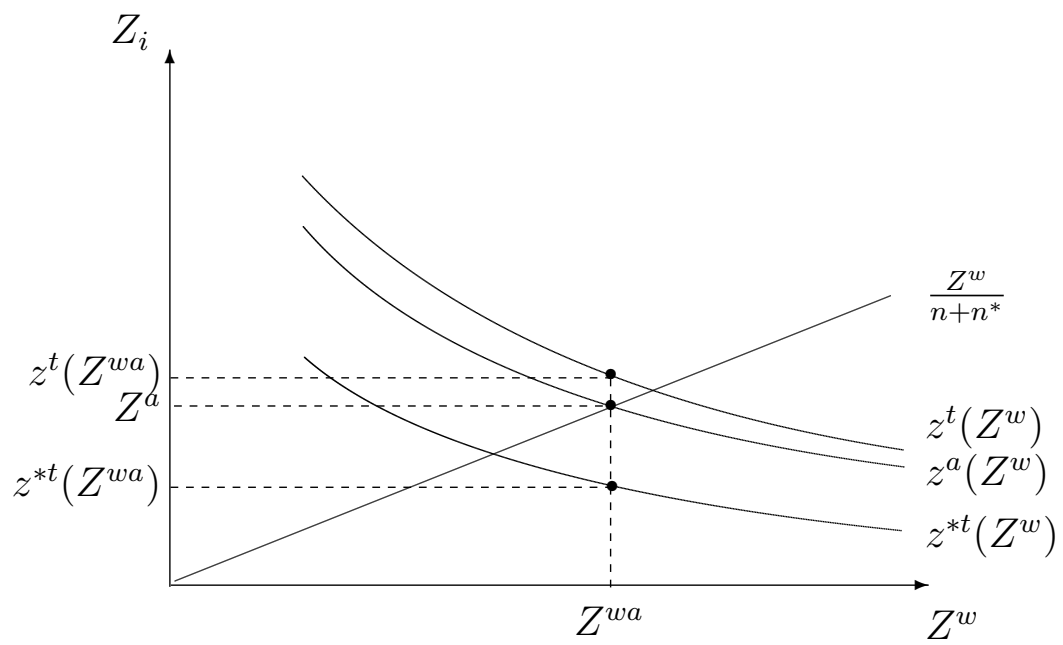

Figure 3: Effects of trade on emissions compared to autarky. 